\title{
Managing an Art Temple in the Light of Empirical Studies
}

\author{
Agnieszka Żarczyńska-Dobiesz, Iwona Janiak-Rejno \\ University of Economics, Wrocław, Poland
}

\begin{abstract}
The aim of this article is to propose a pioneering model of effective theatre management. In the light of the goal, the following thesis has been formulated: Effective management of a temple of art consists in the managing team consciously impacting the key theatre subsystems, taking into account its peculiarity and complexity. The goal and thesis led to the formulation of an explication-verification procedure of empirical studies with the following stages distinguished: selecting research techniques, carrying out pilot study, carrying out basic research, carrying out analysis of the empirical material obtained, and proposing a pioneering model of theatre management. The research procedure specified the scope - the research sample comprised six theatres which constituted the basis of inference, timing — study was conducted in the period from II quarter 2011 till end of 2013, space - territory of four provinces (mazowieckie, małopolskie, wielkopolskie, and dolnośląskie), and the subject matter. It comprised the diagnosis of the following subsystems: the management team's role and efficiency, quality management, work organization, and teamwork management. The pilot results induced the authors to analyze one more area-the organizational culture. In respective theatres, the following employees participated in the research: artistic team (directors, choreographer, stage designers, actors, soloists, and dancers) and administrative team (individuals responsible for performance production and stage attendants - sound engineers, gaffers, stage managers, prompters, and publicity, marketing, finance and personnel staff etc.). In order to get a careful and versatile description of the research question, the methodological triangulation rule was applied according to which the following research techniques were used: surveys, free interviews, individual and group interviews, participant observation, and organizational documents analysis. As final conclusions, the authors create an attempt of a pioneering model of effective management of a temple of art referring to empirical and theoretical parts of the text. The considerations presented in the study are of theoretical-empirical character based on management related literature and empirical studies. The study used a questionnaire, individual and group interviews.
\end{abstract}

Keywords: theatre, managing a theatre, the management team's role and efficiency, quality management, work organisation and teamwork management, organisational culture

\section{Introduction}

The theatre derives from the ancient forms of religious worship. It originated in Dionysia, which was a dramatic festival held in ancient Greece in honor of Dionysus - the god of wine and fertility, birth and death. The crucial point of Dionysia was the dithyramb which is a dialog between coryphaeus-actor and the choir.

Iwona Janiak-Rejno, Ph.D., University of Economics, Wrocław, Poland.

Agnieszka Żarczyńska-Dobiesz, Ph.D., University of Economics, Wrocław, Poland.

Correspondence concerning this article should be addressed to Agnieszka Żarczyńska-Dobiesz, Department of Work and Production Management, University of Economics, Komandorska 118/120, 53-345 Wrocław, Poland. E-mail: agnieszka.zarczynska-dobiesz@ue.wroc.pl. 
The spectators would take seats on theatron forming benches, hence the name theatre rising gradually upwards. In ancient times, the theatre not only provided entertainment, but also had the propaganda, aesthetic and informational role to play. As early as then, the theatre was regarded as the temple of art.

The fall of the Roman Empire and the spread of Christianity resulted in the disappearance of most forms of theater in Western culture for many generations. While the Middle Ages has been huge development stage and forms the geographical spread of the theater, it cannot be compared with the flowering of this art in the Renaissance and Enlightenment. In the 19th century, the development of railway enabled traveling theater groups all over Europe, which resulted in that modern theater has become more secular (Cassady, 1997; Hatch, Kostera, \& Koźmiński, 2010).

Nowadays, the theatre still being the place to create art and consider important and often difficult issues should operate just like a typical enterprise focused on generating profit. Therefore, in order to survive in the highly competitive market, it should perform tasks each system of work has to cope with. One of the most important features of the theatre as a work system is its equifinality which is the ability to achieve specified goals and tasks. Another important characteristic is its high openness to the impact of changing environment necessitating continuous improvement and self-development. Still another characteristic feature of the work system under consideration is its socio-technical nature combining the probabilistic social subsystem with the determined technical subsystem. Therefore, the behavior of the theatre as a whole is predictable only to some extent.

The aim of this article is to propose a pioneering model of effective theatre management. The aim as above can be divided into:

- cognitive goal, comprising identification and analysis of key subsystems affecting the quality of management of the theatre treated as a non-standard enterprise;

- application (utilitarian) goal, comprising identification of limitations in subsystems under investigation which might serve as the basis for practical solutions to be recommended.

In the light of the above goals, the following thesis has been formulated: Effective management of a temple of art consists in the managing team consciously impacting the key theatre subsystems, taking into account its peculiarity and complexity.

The adopted goals and thesis led to the formulation of an explication-verification procedure of empirical studies with the following stages distinguished:

- selecting research techniques;

- carrying out pilot study;

- carrying out basic research;

- carrying out analysis of the empirical material obtained;

- proposing a pioneering model of theatre management.

The research procedure specified the scope (the research sample comprised six theatres which constituted the basis of inference), timing (study was conducted in the period from II quarter 2011 till end of 2013), space (territory of four provinces) and the subject matter. It comprised the diagnosis of the following subsystems: the management team's role and efficiency, quality management, work organization, and teamwork management. The pilot results induced the authors to analyze one more area - the organizational culture.

In order to get a careful and versatile description of the research question, the methodological triangulation rule was applied according to which the following research techniques were used: a questionnaire, individual and group interviews. 


\section{Essence of Creating Performances and Peculiarity of Managing a Theatre}

The main product of the process carried out by the theatre is a theatrical performance, an artistic event. According to Kostera (2007), this type of service is called entertainment service or pastime organization. Using three typology types by Woodward, Thomson, and Perrow, theatre productions can be defined as discrete, intensive, and non-routine (Hatch, 2002). It is discrete, because the number of theatre performances can't be massive. It is intensive, because this non-standardized process is prepared based on non-standard input-output factors. Additionally, for the performance to have a unique atmosphere, the creation process is accompanied by the mission. Finally, it is non-routine, because it is characterized by high variability of tasks with limited opportunity to analyze or repeat them. Large number of problems arising in non-routine technologies and lack of known methods of solving them result in employees' finding themselves in more or less permanent state of uncertainty (Hatch, 2002).

The difficulty of managing the theatre effectively is rooted in its complexity and peculiarity (Menear \& Hawkins, 2001). The theatre complexity results from high degree of diversification of jobs, which usually necessitates individual approach to almost each of them. The theatre peculiarity in turn is determined by the internal diversity of its human resources. Due to substantially different nature of tasks entrusted with them, two main sections in the theatre can be distinguished. The core of a theatre is the theatre ensemble. The second group, irreplaceable in the performance production process though, is the administrative personnel, i.e. stage and performance attendants plus the personnel department, finance department, marketing etc., without whom a professional theatre could hardly exist. If the administrative section operates based on principles similar to those employed in other commercial enterprises, the situation of the artists is much more complex. Very often, beside the typical business relationship they have with the theatre management team, they also enter into the relationship on the artistic ground - where they report to the play director. Thus they operate as entities in a complex matrix structure, having a few more or less formal supervisors, within the relations arising on this ground. Additionally, because of the role they play in the theatre, they usually strive to be treated as a privileged group. It is worth highlighting that despite the undisputed talent they have, they are usually strong personalities detached from the real world and therefore in opposition to implementation of changes in the area of management which is typical for other organizations. For the theatre management, however, the artistic section, on top of the numerous privileges it has, it should also have responsibilities resulting from the established employment relationship (e.g. observe labor discipline principles, be punctual). Apart from the relationships between employees in the theatre and those between the personnel and the management team, the relationship formed between the artist and the audience cannot be passed over. The meeting of those two entities in an art temple is an intimate experience for each of them, a specific network of relations and the place where the subtlest emotions are released. In the context of the above, the key challenge for managers in such institutions is to skillfully reconcile the interests of the two segments and effectively manage the collection of such diverse relationships.

\section{Results of the Diagnosis}

\section{Subsystem-Role and Efficiency of the Management Team}

The way the management team perceives and treats the subordinate personnel is an important aspect in the analysis of the management team's role and efficiency subsystem. Table 1 presents the results. 
Table 1

Results of the Empirical Study of the Management Team's Role and Efficiency Subsystem

\begin{tabular}{|c|c|c|c|c|c|c|}
\hline \multirow[b]{2}{*}{ Statement } & \multicolumn{3}{|c|}{ Artistic section } & \multicolumn{3}{|c|}{ Administrative section } \\
\hline & $\begin{array}{l}\text { Totally } \\
\text { agree }\end{array}$ & $\begin{array}{l}\text { Partly } \\
\text { agree }\end{array}$ & Disagree & $\begin{array}{l}\text { Totally } \\
\text { agree }\end{array}$ & $\begin{array}{l}\text { Partly } \\
\text { agree }\end{array}$ & Disagree \\
\hline Management provides a sense of job security. & 33.3 & 66.7 & 0.0 & 0.0 & 0.0 & 100.0 \\
\hline Management encourages putting ambitious targets. & 83.3 & 16.7 & 0.0 & 0.0 & 33.3 & 66.7 \\
\hline $\begin{array}{l}\text { Management shows involvement in personal development } \\
\text { and skills improvement of the personnel. }\end{array}$ & 100.0 & 0.0 & 0.0 & 0.0 & 16.7 & 83.3 \\
\hline Nominations for the role and promotions are based on merit. & 66.7 & 33.3 & 0.0 & 16.7 & 16.7 & 66.7 \\
\hline $\begin{array}{l}\text { The theatre management style is conducive to good working } \\
\text { atmosphere. }\end{array}$ & 50.0 & 50.0 & 0.0 & 16.7 & 33.3 & 50.0 \\
\hline Management fulfils the promises given to employees. & 50.0 & 50.0 & 0.0 & 16.7 & 16.7 & 66.7 \\
\hline I get feedback on my work from my superior. & 100.0 & 0.0 & 0.0 & 0.0 & 33.3 & 66.7 \\
\hline Management is open to dialogue with employees. & 50.0 & 50.0 & 0.0 & 0.0 & 33.3 & 66.7 \\
\hline In difficult situations, I can count on my superior's help. & 66.7 & 33.3 & 0.0 & 16.7 & 66.7 & 16.7 \\
\hline Management perceives people as valuable asset. & 83.3 & 16.7 & 0.0 & 0.0 & 16.7 & 83.3 \\
\hline I have confidence in the theatre management. & 50.0 & 50.0 & 0.0 & 0.0 & 83.3 & 16.7 \\
\hline Theatre employees are treated with respect. & 16.7 & 33.3 & 50.0 & 16.7 & 16.7 & 66.7 \\
\hline
\end{tabular}

The artistic staff in all theatres under investigation speak with one accord that the management is involved in their development and skills improvement (100\%). Also, they can count on reliable feedback on their work $(100 \%)$. Nearly all the artists of the surveyed theatres believe that the management team treats them a valuable asset $(83.3 \%)$. Not only are they encouraged to put ambitious targets $(83.3 \%)$, but they can count on their superiors' help in difficult situations (66.7\%). Additionally, based on the interviews held, it can be concluded that the artists are convinced of their exceptionality and uniqueness. They often mention the responsibility to the audience for delivering the social mission that has been entrusted with them.

The administrative staff is treated differently by the management. In common opinion, in this section of employees in all theatres under investigation, these employees do not have a sense of job security (100\%). Moreover, as much as $2 / 3$ of the assay claims that the management does not encourage them to set ambitious goals $(66.7 \%)$ or undertake any actions in the training-development area $(66.7 \%)$. The same percentage of the theatre administrative sections believes that decisions regarding promotions are made based on criteria other than merits (66.7\%) and the promises made to employees are not fulfilled (66.7\%). Also, there is no appropriate communication on the line superior-subordinate $(66.7 \%)$. Therefore the fact that in the perception of employees they are not treated with respect is beyond all doubt (66.7\%), which directly impacts the level of confidence they have in the management team. Except for one theatre, the administrative staff declare only partial trust $(83.3 \%)$. According to their opinion, in every second theatre, an unfavorable working atmosphere is predominant $(50 \%)$.

In conclusion, administrative staff of the theatres covered by the research believe that the management team perceives them as less important, less useful, and less necessary than the artistic team, although they do not think of themselves like that. In their opinion, the theatre would not be able to operate in the competitive economy conditions without their work, therefore they find the fact of being treated instrumentally as those playing only supporting role highly demotivating and unjustified. 


\section{Subsystem-Work Quality Management}

The work quality is a crucial subsystem for the artistic value of the performance. Employees in nearly all of the theatres in this research, regardless of their functions, speak in one accord that the overriding commitment of the theatre to the audience is to deliver top level performances (artistic section $100 \%$; administrative section $83.3 \%$ ). Table 2 presents the results.

Table 2

Results of Empirical Study of the Work Quality Management Subsystem

\begin{tabular}{|c|c|c|c|c|c|c|}
\hline \multirow[b]{2}{*}{ Statement } & \multicolumn{3}{|c|}{ Artistic section } & \multicolumn{3}{|c|}{ Administrative section } \\
\hline & $\begin{array}{l}\text { Totally } \\
\text { agree }\end{array}$ & $\begin{array}{l}\text { Partly } \\
\text { agree }\end{array}$ & Disagree & $\begin{array}{l}\text { Totally } \\
\text { agree }\end{array}$ & $\begin{array}{l}\text { Partly } \\
\text { agree }\end{array}$ & Disagree \\
\hline $\begin{array}{l}\text { The key commitment of the theatre to the audience is to } \\
\text { produce top quality performances. }\end{array}$ & 100.0 & 0.0 & 0.0 & 83.3 & 16.7 & 0.0 \\
\hline Work quality is a priority with the theatre personnel. & 50.0 & 33.3 & 16.7 & 0.0 & 33.3 & 66.7 \\
\hline $\begin{array}{l}\text { I understand how my work affects the quality of } \\
\text { performances. }\end{array}$ & 83.3 & 16.7 & 0.0 & 16.7 & 83.3 & 0.0 \\
\hline $\begin{array}{l}\text { All departments in the theatre cooperate with one another to } \\
\text { ensure top quality. }\end{array}$ & 0.0 & 16.7 & 83.3 & 0.0 & 33.3 & 66.7 \\
\hline $\begin{array}{l}\text { Training sessions organized by the theatre enable to perform } \\
\text { work in accordance with the requirements. }\end{array}$ & 100.0 & 0.0 & 0.0 & 0.0 & 16.7 & 83.3 \\
\hline $\begin{array}{l}\text { The theatre management does not tolerate work below } \\
\text { specified standards. }\end{array}$ & 66.7 & 33.3 & 0.0 & 0.0 & 33.3 & 66.7 \\
\hline
\end{tabular}

In the context of such declarations, the clear-cut opinions of the administrative staff in as many as four theatres (66.7\%) according to which the management tolerates work below the specified standards and the quality is not always a priority seem to be dubious. The artists take a different stand on this issue. In their opinion, low quality work $(83.3 \%)^{1}$ effectively meaning work below the specified standards, is unacceptable (66.7\%). The discrepancy in opinions is reflected in the lack of mutual cooperation, perceived by the two sections of the theatre, to ensure the required quality (artistic section 83.3\%; administrative section 66.7\%). Also, the artists (83.3\%) much more often than the administrative staff claim that they fully understand the relation between their work and the final quality of the performance. This relationship is perceived by the administrative staff in only one of the theatres $(16.6 \%)$; in the remaining five, they understand it only partly (83.3\%). Another disturbing signal is the gross negligence they find in the area of their important competence development (Table 2). In the interviews held, it was stressed that the training budgets were intended mainly for the artists' skills improvement which causes justified discontent and sense of unfairness amongst other staff.

\section{Subsystem - Work Organization Management}

Work in the theatre is difficult to plan and organize. If the administrative staff usually have traditional working hours ${ }^{2}$, the artists, in spite of that rehearsals are usually held at fixed hours, often fail to conform to the accepted time frames. From the observations and interviews held, it follows that artists find it difficult to adapt to formal rules and imposition of rigid rules meets with their immediate objection.

Analysis of the work organization management subsystem pointed out significant discrepancies between the opinions of the very theatres being surveyed as well as those of the administrative and artistic section employees. Table 3 presents the results.

\footnotetext{
${ }^{1}$ Fifty percent of the artistic sections of the theatres totally agree with this statement and $33.3 \%$ partly agrees.

2 Departures from the rule happen, e.g. in the period preceding premiere.
} 
In the opinion of the administrative staff in majority of the theatres covered by the research, their work is not organized properly (66.7\%). Artistic teams in as many as four theatres believe the opposite $(66.7 \%)$. The remaining employees of both sections find the work organization only partly correct (33.3\%).

Table 3

Results of Empirical Study of the Work Organization Management Subsystem

\begin{tabular}{|c|c|c|c|c|c|c|}
\hline \multirow[b]{2}{*}{ Statement } & \multicolumn{3}{|c|}{ Artistic section } & \multicolumn{3}{|c|}{ Administrative section } \\
\hline & $\begin{array}{l}\text { Totally } \\
\text { agree }\end{array}$ & $\begin{array}{l}\text { Partly } \\
\text { agree }\end{array}$ & Disagree & $\begin{array}{l}\text { Totally } \\
\text { agree }\end{array}$ & $\begin{array}{l}\text { Partly } \\
\text { agree }\end{array}$ & Disagree \\
\hline Work in the theatre is well organized. & 66.7 & 33.3 & 0.0 & 0.0 & 33.3 & 66.7 \\
\hline Work goals in the theatre are clearly defined. & 66.7 & 16.7 & 16.7 & 66.7 & 33.3 & 0.0 \\
\hline $\begin{array}{l}\text { I think there are too many constraints, rules, and procedures } \\
\text { in the theatre. }\end{array}$ & 83.3 & 16.7 & 0.0 & 0.0 & 16.7 & 83.3 \\
\hline $\begin{array}{l}\text { I often lack the information on what is happening in the } \\
\text { theatre. }\end{array}$ & 0.0 & 33.3 & 66.7 & 50.0 & 50.0 & 0.0 \\
\hline I solve running issues without consulting the management. & 66.7 & 33.3 & 16.7 & 50.0 & 50.0 & 0.0 \\
\hline I am satisfied with the technical equipment at my work place. & 33.3 & 33.3 & 33.3 & 33.3 & 33.3 & 33.3 \\
\hline Health and safety regulations are observed in the theatre. & 83.3 & 16.7 & 0.0 & 83.3 & 16.7 & 0.0 \\
\hline
\end{tabular}

Different opinions concern also the constraints existing in the theatre. Majority of the artistic sections of the theatres being surveyed believe that the number of rules and procedures in place is far too big $(83.3 \%)$. The administrative sections believe the opposite (83.3\%). In their opinion, the lack of rules of conduct may lead to organizational chaos. The interviews held and the participant observance in particular indicate again that there are two significantly different sections existing within a common work subsystem. The artists perceive rigid regulations as redundant constraints whilst the remaining staff find them to be an important element of an effectively managed enterprise.

Lack of running information on what is happening in the theatre is another proof that there are problems in the area of management. According to the administrative staff ${ }^{3}$, in numerous situations, the lack of information caused misunderstandings which negatively affected not only the atmosphere at work but the quality of work in the first place. The artists take a different stand on this issue claiming that they have the necessary information $(66.7 \%)$.

In the light of identified differences in opinions, both sections of the theatres being surveyed agree that the goals specified by the theatre management are clear-cut and the conditions of their material working environment are prepared properly, both in terms of technical equipment and observance of health and safety regulations (Table 3).

\section{Subsystem-Teamwork Management}

One of the significant factors affecting the theatre management effectiveness is the ability to manage the staff made up of both the artistic and the administrative sections. Theatrical productions require involvement and cooperation of many people playing different roles in the theatre, appropriate allocation of tasks and their efficient coordination. Usually the theatre staff's work is based on two fundamental forms: teamwork being the basic and leading one and individual work being supplementary to teamwork. On one hand, the artist tends to strive not only to be recognizable but to win the recognition through his work on the stage; on the other hand,

\footnotetext{
${ }^{3}$ In every second, theatre employees think that they often lack up-to-date information about what is happening at the theatre. Second-half only partly agree that this statement is correct.
} 
however, he/she should be aware that his/her individual career is largely dependent on cooperation with the whole team and the joint responsibility for the final effect. Although the nature of professional success of the administrative staff has a different dimension than that of the artistic section, the form of their work is analogous - with both based on the teamwork principle combined with striving for success on the individual level, too. Since the line between teamwork and individual work in the theatre is very thin and subtle, mutual understanding and cooperation are required from both the management team and the human resources making up the theatre.

The research conducted does not entirely confirm the above statements, though. If the artistic teams of the theatres covered by this research are advocates of the above mentioned behaviors and attitudes, the administrative staff do not entirely share this enthusiasm. Table 4 presents the results.

Table 4

Results of Empirical Study of the Teamwork Management Subsystem

\begin{tabular}{|c|c|c|c|c|c|c|}
\hline \multirow[b]{2}{*}{ Statement } & \multicolumn{3}{|c|}{ Artistic section } & \multicolumn{3}{|c|}{ Administrative section } \\
\hline & $\begin{array}{l}\text { Totally } \\
\text { agree }\end{array}$ & $\begin{array}{l}\text { Partly } \\
\text { agree }\end{array}$ & Disagree & $\begin{array}{l}\text { Totally } \\
\text { agree }\end{array}$ & $\begin{array}{l}\text { Partly } \\
\text { agree }\end{array}$ & Disagree \\
\hline I prefer teamwork to individual work. & 83.3 & 16.7 & 0.0 & 33.3 & 33.3 & 33.3 \\
\hline $\begin{array}{l}\text { As a rule, I don't expect help with my work from my } \\
\text { colleagues. }\end{array}$ & 16.7 & 16.7 & 66.7 & 100.0 & 0.0 & 0.0 \\
\hline There is an atmosphere of competition in the theatre. & 167 & 16.7 & 66.7 & 83.3 & 0.0 & 16.7 \\
\hline $\begin{array}{l}\text { We try to behave in an open and honest way observing the } \\
\text { principles of ethics. }\end{array}$ & 66.7 & 16.7 & 16.7 & 16.7 & 16.7 & 66.7 \\
\hline Team achievements are celebrated. & 100.0 & 0.0 & 0.0 & 0.0 & 0.0 & 100.0 \\
\hline $\begin{array}{l}\text { The theatre is interested in the employees' ideas concerning } \\
\text { improvements of the work of the theatre as a team. }\end{array}$ & 33.3 & 33.3 & 33.3 & 33.3 & 0.0 & 66.7 \\
\hline Work in the theatre is a pleasure. & 83.3 & 16.7 & 0.0 & 0.0 & 50.0 & 50.0 \\
\hline
\end{tabular}

Hence, analysis of this subsystem serves as one more confirmation of two almost separate teams existing within one entity. In comparison:

- artists in $2 / 3$ of the surveyed theatres prefer teamwork to individual work (66.7\%); while this type of work is preferred by only every third administrative section (33.3\%);

- artists in only one theatre do not typically expect help with their work from their colleagues $(16.7 \%)$, while others, to a lesser or greater extent, appreciate such support (83.3\%). Additionally, they declare that they try to behave in an open and honest way respecting the principles of ethics (66.7\%), denying the existence of the atmosphere of competition in the theatre $(66.7 \%)^{4}$. The administrative sections covered by this research represent almost totally different attitude. The structure of results (Table 4) indicates that none of the sections being surveyed counts on the colleagues' help (100\%). As many as five of them claim that there is an atmosphere of competition in the theatre $(83.3 \%)$ with vast majority denying observing the principles of ethics at work (66.7\%);

- according to all artistic teams being surveyed, team achievements are especially celebrated in their theatre without a single administrative section confirming this opinion.

Summing up, artists in as many as five theatres commonly declare (83.3\%) that work is a pleasure to them. Such a declaration has not been confirmed by any of the administrative sections being surveyed $(0.0 \%)$.

\footnotetext{
${ }^{4}$ The participant observation conducted is not entirely consistent with the artists' declarations. In reality, huge tension and feeling of competition can be observed during castings.
} 


\section{Analysis of the Organizational Culture}

The organizational culture in the theatre can be understood as a symbolic system that gives meaning to its existence, facilitates communication, and affects employees' motivation being a crucial component in the building of the working atmosphere and integration among its members. It is the culture where employees tend to seek support and stabilization of interpersonal relationships.

A strong correlation between the organizational culture and the subsystems being considered induced the authors to thoroughly analyze it. To this end, closed questions with semantic differentiation scale were used. The study of the organizational culture of the theatre was conducted based on the culture dimensions specified by Hofstede (2000) in Table 5. It provides valuable information on real behaviors of the employees. It serves as frame of reference indicating the behaviors to be fostered in the theatre as well as those to be avoided.

\section{Table 5}

Results of the Organizational Culture Empirical Study Conducted Based on Culture Dimensions by Hofstede and the Semantic Differentiation Scale

\begin{tabular}{|c|c|c|}
\hline Extreme rating & $\max \quad 0 \quad \max$ & Extreme rating \\
\hline Individualism & & Team spirit $^{5}$ \\
\hline Small distance of power & & Big distance of power \\
\hline Low penchant for risk & & High penchant for risk \\
\hline Masculinity & & Femininity \\
\hline Priority of procedures & & Priority of results \\
\hline Care for employees & & Care for tasks \\
\hline Membership & & Professionalism \\
\hline Open system & & Closed system \\
\hline Loose control & & Tight control \\
\hline Strong motivation & & Weak motivation \\
\hline Formal communication & & Informal communication \\
\hline Optimism & & Pessimism \\
\hline Faith in success & & Lack of faith in success \\
\hline Leaders in place & & No leaders in place \\
\hline Group slightly susceptible to leaders & & Group highly susceptible to leaders \\
\hline Sense of security & & No sense of security \\
\hline Development opportunities & & No development opportunities \\
\hline Integration & $\stackrel{b}{p}$ & Disintegration \\
\hline ............... & \multicolumn{2}{|l|}{ Administrative section } \\
\hline- & \multicolumn{2}{|l|}{ Artistic section } \\
\hline
\end{tabular}

The analysis results depict and explain the essential differences between the two sections in the theatre (Table 5). In general, what differentiates them the most is the attitude to formal rules and procedures of conduct. Artists are characterized by small distance of power, high penchant for risk, loose control, focus on results, high motivation and strive for integration, informal communication, faith and optimism. The artistic teams strongly identify themselves with the theatre, the stage; they have the sense of community where superficial relationships are out of question. They carry on professional friendships to private life. Theatre is like a family

\footnotetext{
${ }^{5}$ This dimension is called collectivism by Hofstede.
} 
to many of them. As regards the administrative section employees, lack of formalization and standardization considerably hinders their daily work generating misunderstandings between respective departments, and hence their desire to formalize their work (Table 5). Divergent preferences of respective theatre sections regarding desirable attitudes and behaviors which will set the basis for the key dimensions of culture effectively result in conflicts, weakening of the communication channels, and inhibition of the organizational development leading to feelings of disappointment and dissatisfaction amongst the personnel. Therefore, the strive for mutual adjustment and understanding between the two seems fully justified.

\section{Conclusions}

Many employees declare that theatre is a special place and working there is a pleasure combined with getting a lot of satisfaction. Dimension of this work is not purely financial; artists doing this job want to pursue their own passions and interests. To a large extent, the determinant of that passion is the prestige connected with the direct contact with art, lack of routine, and the recognition and appreciation of the audience. Nowadays, however, delivery of a single mission which is dissemination of culture is utopia; the intensity of economic changes necessitates the need to survive in the competitive market. According to Kostera (2007), organizations such as theatres operate in the area of values and emotions under continuous surveillance of the audience requiring undisputed talent, professionalism, courage, and responsibility. Managing an art temple must definitely include the elements of the modern management. The ability to prevent problematic situations and reduce their negative influence on the company largely depends on the competence of the management team. Managers are also responsible for taking the work system through the process of changes, often difficult, going on in the market and for using it as a positive source of renewal. Managing a theatre consists in the management team taking up the roles which are adjusted to the phase of change the organization is currently at. According to Stoner, Freeman, and Gilbert (2001), managers work with people and through people, with everybody on every level, inside or outside their organization, who may contribute to achieving objectives of individuals and the whole enterprise. They are responsible not only for their work but first of all for the work of others. They serve as the most important means of communication. The managers' awareness of the importance and superiority of these roles (work with people and related responsibility) should induce them to rationally use the resources they have at disposal.

As the final conclusions, the authors create an attempt of a pioneering model of effective management of a temple of art referring to empirical and theoretical parts of the text. For effective theatre management, the managers' awareness of its distinctiveness compared to a typical enterprise is a prerequisite. Designing and managing such a peculiar work system are a key challenge for the management. According to the thesis formulated, the theatre management consists in the managing team consciously impacting the key theatre subsystems, taking into account its peculiarity and complexity. It is worthwhile to stress that the organizational culture has a great impact on the management process by defining the boundaries for the actions being taken by the management team. Bearing in mind its importance, it is the area that requires continuous monitoring by the management team to ensure that it is consciously moulded and possible problems are prevented. The desirable direction for organizational culture management in the theatre is presented in Table 6.

It is important not to strive for a total compromise between the two theatre sections. Although they make up one culture, uniformity of this culture seems not only unnatural but impossible to achieve, too. According to Kostera (2007), even totalitarian organizations have their pockets of resistance and dissent, because culture 
does not need to integrate everybody and it surely does not have to consolidate in the same way. Especially in the theatre, there are subcultures associated with different roles of employees, their different significance, the positions they hold and their place in the hierarchical structure. It is important that the existing subcultures make it possible for an agreement to be reached above those differences, at least on key dimensions. The party responsible for reaching the above agreement and hence managing the theatre effectively is the management team.

Table 6

Desirable Direction for Organizational Culture Management in the Theatre

\begin{tabular}{|l|l|}
\hline Dimensions & Desirable direction of effective management \\
\hline Individualism within collectivism & $\begin{array}{l}\text { Balance between individual professionalism and stimulating employees' behaviors towards } \\
\text { the sense of belonging to the group-the theatre which has common goals and benefits. }\end{array}$ \\
\hline Small distance of power & $\begin{array}{l}\text { All employees should be treated the same regardless of the type of work they do and their } \\
\text { contacts with the management should be characterized by the sense of cooperation and } \\
\text { mutual help. }\end{array}$ \\
\hline $\begin{array}{l}\text { Balancing between masculinity and } \\
\text { femininity }\end{array}$ & $\begin{array}{l}\text { Motivate employees to assume active attitude and behaviors, focus personnel on } \\
\text { integration, cooperation and mutual help. Build the atmosphere of healthy competition. }\end{array}$ \\
\hline $\begin{array}{l}\text { Balancing between the priority of of } \\
\text { results and the priority of procedures }\end{array}$ & $\begin{array}{l}\text { Motivate employees to deliver the set goals allowing greater flexibility in the existing rules } \\
\text { and procedures relative to the role of the respective employee, current conditions and } \\
\text { circumstances. }\end{array}$ \\
\hline $\begin{array}{l}\text { Balancing between goal delivery and } \\
\text { care for employees }\end{array}$ & $\begin{array}{l}\text { Treat employees as subjects in order to reinforce their sense of importance for the theatre, } \\
\text { job security and identify and satisfy their needs. }\end{array}$ \\
\hline Open system & $\begin{array}{l}\text { Build the atmosphere of friendship based on an open, reliable, running, and two-way } \\
\text { communication amongst all members of theatre personnel. }\end{array}$ \\
\hline Optimal control level & $\begin{array}{l}\text { Work out, jointly with employees, the rules and principles of conduct, departure from strict } \\
\text { work discipline. }\end{array}$ \\
\hline Strong motivation & Mould high level of motivation (both internal and external) in employees to perform tasks. \\
\hline Development opportunities & $\begin{array}{l}\text { Perceive employees development as an indispensable investment, promotion, and support } \\
\text { for the training activities of the personnel. }\end{array}$ \\
\hline Balanced level of risk taken & $\begin{array}{l}\text { Reduce the level of risk perceived by employees in the face of new, unknown or uncertain } \\
\text { situations whilst envisaging potential effects of the risk being taken at the same time. }\end{array}$ \\
\hline
\end{tabular}

\section{References}

Cassady, M. (1997). Theatre: An introduction. Lincolnwood: NTC Publishing Group.

Hatch, M. J. (2002). Teoria organizacji. Warszawa: Polskie Wydawnictwo Naukowe

Hatch, M. J., Kostera, M., \& Koźmiński, A. K. (2010). Trzy oblicza przywództwa: menedżer, artysta, kaptan. Warszawa: Wydawnictwa akademickie i profesjonalne.

Hofstede, G. (2000). Kultury i organizacje. Warszawa: Polskie Wydawnictwo Ekonomiczne.

Kostera, M. (2007). Kultura organizacji. Badania etnograficzne polskich firm. Gdańsk: Gdańskie Wydawnictwo Psychologiczne.

Menear, P., \& Hawkins, T. (2001). A phaidon theatre manual: Stage management and theatre administration. London: Phaidon Press.

Stoner, J. A. F., Freeman, R. E., \& Gilbert, D. R. Jr. (2001). Kierowanie. Warszawa: Polskie Wydawnictwo Ekonomiczne. 